\title{
O ESPAÇO POÉTICO: CRÍTICA SOCIAL E ESTRATÉGIAS LINGUÍSTICAS EM JOSÉ CRAVEIRINHA
}

Fernanda Dusse

(Mestranda pela PUC /MG)

\section{RESUMO}

A partir do conceito de cronótopo, de Mikhail Bahktin, busca-se perceber como o sistema poético apresenta a configuração espaço-temporal, ilustrando a mesma em poemas de fundo político-sociais do moçambicano José Craveirinha.

PALAVRAS-CHAVE: José Craveirinha, espaço, cronótopo.

\begin{abstract}
Considering Mikhail Bahktin's concept of chronotope, this work aims to analyze how the poetic system presents the spatial-temporal configuration, illustrating such in political-social poems by Mozambican José Craveirinha.
\end{abstract}

KEYWORDS: José Craveirinha, space, chronotope. 


\section{INTRODUÇÃO}

Este trabalho tem como objetivo discutir a questão do espaço na poesia, recuperando teorias sobre o espaço de autores como Milton Santos ou Doreen Massey e apresentando-as a partir de textos do moçambicano José Craveirinha. O desafio de observar a obra do poeta a partir das lentes propostas pelos geógrafos surgiu após perceber que a ênfase dada às questões sócio-culturais na crítica poética é ainda rasa, já que a mesma se concentra, primordialmente, nas questões estilísticas do texto. No entanto, caminhando na contramão da crítica, o fazer poético sempre teve papel importante na difusão de ideologias e denúncias sociais, e seus autores utilizam do ritmo e da condensação como estratégias discursivas para transmitir mensagens de cunho político e social.

Dessa forma, meu interesse nesse ensaio é perceber quais são os elementos textuais empregados por Craveirinha para que suas poesias retratem, ao mesmo tempo, questões do momento histórico de seu país e reflexões sobre a condição cidadã e humana. A questão do espaço, portanto, se desdobra em considerações sobre o espaço político - fortemente marcado pelas lutas nacionais - e o espaço da arte, sempre infinito em sua apresentação das angústias dos homens.

Além disso, é importante salientar que a literatura representa um espaço frutífero para a discussão das questões sociais, já que nela partimos da expressão artística - que, ao contrário dos textos científicos, não tem preocupação com a veracidade - para, inseridos nessa expressão livre, encontrarmos os conflitos e ideologias de um povo. Segundo Antonio Candido:

a literatura corresponde a uma necessidade universal que deve ser satisfeita sob pena de mutilar a personalidade, porque pelo fato de dar forma aos sentimentos e à visão de mundo, ela nos organiza, nos liberta do caos e portanto nos humaniza (CANDIDO, 1977, p. 186)

Dessa forma, conhecer a literatura é descobrir ou reconhecer-se nas fabulações alheias, percebendo como elas se inserem em contextos político-sociais e como contam a história da luta humana por liberdade.

Na obra de José Craveirinha, essa questão se mostra ainda mais forte, já que, produzida durante a ditadura salazarista, ilustra a luta popular por participação política e pela paz com consciência social. Sendo assim, meu interesse em perceber como a poesia retrata a condição histórico-geográfica deverá passar também por um breve mapeamento da situação política do país e pela relevância das manifestações artísticas nesse contexto específico.

\section{ESPAÇOS: DEBATES}

O termo espaço público tem sido usado ao longo da história da humanidade para tratar dos espaços deliberados para o convívio comunitário. Originária do latim, a palavra publicus significa, literalmente, do 
povo e é oposta a privado, cujo sentido remete à privação, ao espaço do indivíduo. Entretanto, a condição do espaço público não é estática, e seu uso está relacionado aos hábitos de determinada sociedade. Dessa forma, a relação dos cidadãos com os espaços públicos e privados durante a Grécia Antiga ou a Idade Média pouco tem a ver com a percepção dos homens modernos sobre o conceito.

Um fator de enorme importância para a mudança de perspectiva na Modernidade foi a migração do ambiente de trabalho, do espaço doméstico para o público. Isso porque a invenção de máquinas capazes de produzir em larga escala estabeleceu novos parâmetros para a convivência social, determinando, por exemplo, a lógica do consumo e do lucro, e delimitou novas fronteiras espaciais, como as propriedades burguesas, as áreas urbanas e, até mesmo, as nações.

Isso nos mostra que a relação dos homens com objetos (ferramentas, máquinas, produtos de consumo) é também fundamental para definir sua relação com o espaço. Dessa forma, o espaço público não remete apenas à convivência interpessoal, mas também às relações dos homens com os objetos e a natureza. Segundo Milton Santos, "o espaço é igual à paisagem mais a vida nela existente, é a sociedade encaixada na paisagem; a vida que palpita conjuntamente com a materialidade" (SANTOS, 1988, p. 26). Sendo assim, para o autor, o espaço só existe como conjunto da sociedade com a natureza e os objetos: todos eles são, portanto, partes de um único processo de percepção geográfica e social.

Além disso, a reflexão de Santos aponta para a constante reconfiguração do espaço, afinal, se ele é fruto da ação dos homens sobre a paisagem, não está acabado, sendo, pelo contrário, reconstruído e ressignificado de acordo com o momento histórico. Dessa forma, é impossível compreender o espaço separado do tempo, já que a percepção da realidade se baseia na ação simultânea dos dois.

Nos estudos literários, Bakhtin já havia evidenciado a importância da percepção conjunta de tempo e espaço. Segundo o autor:

O cronótopo como materialização privilegiada do tempo no espaço é o centro da concretização figurativa da encarnação do romance inteiro. Todos os elementos abstratos do romance, as generalizações filosóficas e sociais, as ideias, as análises das causas e dos efeitos, gravitam ao redor do cronótopo, graças ao qual se enchem de carne de sangue e se iniciam no caráter imagístico da arte-literária. (BAKHTIN, 1993, p. 356)

Ao combinar os prefixos crono (tempo) e topo (espaço), Bahktin aponta para o caráter relacional das duas instâncias, mostrando como é impossível perceber um na ausência do outro. Ele afirma, então, que o romance se constrói a partir do cruzamento e do confronto dos cronótopos, capazes de evidenciar a imagem do sujeito em seu espaço social e momento histórico específicos. 
Bakhtin continuou sua análise romanesca a partir de estudos sobre a linguagem, único instrumento de um escritor na construção ficcional. Ele concluiu que toda linguagem se organiza dialogicamente, isto é, a partir da troca de mensagens por sujeitos com visões de mundo distintas. Por esse motivo, segundo o autor, o diálogo traz em si uma tensão, movida pelo desejo de apresentar ao outro sua realidade particular, e que resulta em um confronto de diferentes vozes sociais. Dessa forma, o espaço público se caracteriza também por arena de debates, local para o encontro e para a convivência social intermediada pela linguagem.

$\mathrm{Na}$ análise literária, particularmente, o diálogo apresenta diversas faces. Há os diálogos presentes na obra, aos quais podemos chamar “diálogos internos". São eles que fortalecem a construção subjetiva de uma personagem, pois evidenciam como ela se relaciona com as outras. Além disso, são também usados como estratégias para a apresentação de pontos de vista antônimos e demonstram como o debate se configura naquele espaço específico.

Há também os "diálogos externos" travados entre o autor e os homens de seu tempo, visto que a obra literária é um espaço de fala para o primeiro. Dessa forma, é possível pensar como o texto transmite as ideologias e percepções de seu autor, observando-as em contraste com os outros discursos marcados naquele espaço histórico. Isso porque o discurso literário também está inserido na rede de diálogos sociais e, por esse motivo, apropria-se, responde ou repudia os demais.

A literatura, portanto, dá novos significados para os estudos espaciais. Sua construção possibilita a análise do espaço ficcional, interno, cuja principal característica é ser composto, exclusivamente, de linguagem. Há também abertura para pensarmos a literatura como sistema, ou seja, a contribuição social de determinada obra para o espaço histórico. Neste trabalho, pretendo estabelecer conexões entre ambos, mostrando como a construção linguística do espaço poético interage e fortalece o debate sobre a organização ideológica e material do espaço histórico.

\section{A POESIA COMO ESPAÇO SOCIAL}

A maior parte dos teóricos que se propôs a estudar o tempo e o espaço na literatura concentrou suas análises no romance. Tal opção justifica-se pelo caráter linear da estrutura romanesca, que acompanha a trajetória de seus personagens ao longo de um período bem definido. A poesia, por sua vez, apresenta-se como uma fissura no tempo, um espaço de congelamento e alargamento temporal que nos permite perceber os conflitos humanos com mais detalhamento. Massaud Moisés afirma que

a poesia é a-histórica, a-narrativa e a-geográfica [pois] as emoções, sentimentos e conceitos que integram um poema ignoram qualquer sucessividade análoga à do tempo no relógio, e apenas se arquitetam conforme 
um nexo psicológico ou inerente à própria substância da narrativa, dir-se-ia um nexo emotivo-sentimental-conceitual. (MOISÉS, 1998. p. 43)

Dessa forma, a poesia surge como um sistema cronotópico particular, com características que desafiam a compreensão de espaço e tempo por não serem físicas nem lineares. Ao contrário, o poema se constrói como círculo, "porquanto o primeiro verso e o último coexistem numa circunferência, verdadeiramente à semelhança de uma galáxia - em perpétuo dinamismo" (MOISÉS, 1998. p. 44).

Percebendo, então, a poesia como sistema espacial, torna-se fundamental delimitar características que nos possibilitam afirmar que textos de diferentes estilos habitam o sistema poético. Em primeiro lugar, a forma desponta como característica particular da estruturação espacial da poesia. A escrita em versos verticaliza o texto, transformando-o em uma vertigem, que nos tonteia pela apresentação transparente de nossos conflitos e angústias.

A poesia, portanto, nos põe em contato com o abismo desde sua primeira imagem: nela, a forma está em queda livre e junto caem os conceitos histórico-geográficos e a percepção linear do mundo. Por isso, a poesia é um espaço para a tomada de consciência, a reflexão sobre possibilidades outras de se organizar a história, a geografia e a sociedade. Octavio Paz afirma que

sem palavras comuns não existe poema; sem palavra poética tampouco existe sociedade, Estado, Igreja ou comunidade alguma. A palavra poética é história em dois sentidos complementares, inseparáveis e contraditórios: no de constituir um produto social e no de ser uma condição prévia para a existência de toda a sociedade. (PAZ, 2001, p. 66)

A poesia se localiza no cerne do espaço social e, ao mesmo tempo, fora dele. Se, por um lado, ela é fundamental para as relações humanas, por expô-las e debatê-las, por outro, ela se consagra como espaço individual - de escrita ou leitura - que não se dissipa nas mudanças históricas. Octavio Paz, falando mais uma vez sobre a capacidade de renovação infinita da palavra poética, afirma que "ouvir essa voz [poética] é ouvir o próprio tempo, o tempo que passa e que, apesar disso, volta, transformado em umas quantas sílabas cristalinas." (PAZ, 2001, p. 74).

Nesse momento, ao referir-se às sílabas como "cristalinas", Paz chama atenção para outra particularidade do poema: o ritmo. Na poesia, a palavra aparece em sua forma mais transparente, assumindo seu caráter sonoro e representativo. Por isso, os símbolos linguísticos se multiplicam, dando significados não apenas à matéria a qual aludem, mas também referindo-se, metalinguisticamente, à estruturação verbal do pensamento. Dessa forma, a poesia coloca a relação entre símbolo e som em evidência, ao mostrar que, embora às vezes arbitrários, os sons e os símbolos são também construções humanas. 
O jogo poético não objetiva a representação exata do mundo, mas a apresentação verbal - rítmica, lúdica, incompleta - da realidade subjetiva. Alfredo Bos afirma que “integrar o som no símbolo não é esvaziá-lo de suas latências simbólicas. Ao contrário, integrar é respeitar o modo de ser do signo" (BOSI, 2004, p. 66); afinal, a palavra poética faz emergir o caráter simbólico da linguagem, afastando-a da ideia de traduzir experiências e aproximando-a do conceito de interpretação.

Se todo discurso objetiva transportar a matéria para a linguagem, o discurso poético faz também o caminho contrário: transforma a linguagem em matéria. Segundo Bosi, "toda grande poesia nos dá a sensação de franquear impetuosamente o novo intervalo aberto entre a imagem e o som" (BOSI, 2004, p. 31). Isso acontece porque na poesia as palavras se apresentam como peças: escolhidas, contadas, tratadas. Assim, ao mesmo tempo em que evidenciam o caráter simbólico e abstrato da linguagem, elas dão uma dimensão concreta, palpável, para o discurso.

Por isso, a questão da forma na poesia transita por todas as suas esferas, da análise do todo (o poema impresso no papel) ao mínimo (a escolha de cada palavra-matéria). Ela é, portanto, o elo entre cada parte do poema, evidenciando o trabalho do autor na construção do texto e determinando algumas particularidades do sistema poético. Assim como em todo discurso, a palavra na poesia é um ícone que remete a uma imagem. Entretanto, é através da forma que a poesia une esse ícone a outros, transformando o todo em um símbolo que não resulta na soma, mas na complexa interação de suas partes.

Refletindo mais uma vez sobre a poesia como sistema espacial, podemos afirmar que sua construção é marcada pela intercalação de matéria (linguagem) e vazio. Isso fica evidente já em uma análise superficial, visto que, como toda manifestação verbal, o verso é composto por palavras e espaços, o que determina o ritmo de leitura. Além disso, a estruturação do poema no papel inclui uma ampla margem à direita e uma divisão em versos e estrofes - e não em frases e parágrafos. Dessa forma, o poema questiona nossa prática de leitura, ao fazer com que acompanhemos a descida dos versos, a pulsação das palavras, e não, estritamente, a pontuação e as regras gramaticais.

Mais que isso, o vazio na poesia aponta para a pluralidade ali presente. Pela condição simbólica da palavra, não podemos nunca buscar nela um fim, uma essência. Contudo, essa constatação é ainda mais evidente na poesia, espaço, por excelência, da metáfora. A linguagem poética não tem o propósito de ensinar ou realizar-se, ela reconhece o valor icônico da palavra e vale-se disso para sugerir, a partir do som, imagens várias. Além disso, o discurso poético reconhece a subjetividade e a ausência de uma realidade exterior. Dessa forma, o poeta não escreve com a intenção de apresentar o mundo para outrem, mas, ao contrário, vale-se da organização discursiva para expor e refutar, pela sátira presente em toda simbolização, a imagem. 
A partir dessas reflexões, é preciso rever as características da poesia social. Afinal, o discurso político é geralmente marcado pelo uso de frases assertivas e pela anulação da subjetividade, já que sua intenção é, quase sempre, convencer os ouvintes/leitores a compartilhar do pensamento de quem o profere. Dessa forma, é difícil perceber a conjugação da poesia espaço de fala subjetiva - com a política, especialmente quando partidária.

Entretanto, muitos são os poetas que expõem em seus escritos ideologias, lutas e crenças político-sociais. É possível perceber que os textos desses autores, vistos a princípio como paradoxais, são na verdade marcados por uma combinação minimalista de subjetividade e consciência social. Além disso, por estarem em um entre-lugar, eles revisam ambas as crenças, refletindo sobre as condições para a convivência comunitária justa e, também, sobre o respeito à individualidade e à liberdade.

É por esse caráter integrador que Octavio Paz define a poesia como "a outra voz". Segundo o autor, ela é a condensação da voz de todos e de ninguém, a caracterização do momento histórico e sua paródia (PAZ, 2001). A poesia social, particularmente, o é ainda mais: ela é a proclamação ideológica e a ausência de síntese, é um convite para a reflexão e o debate, um espaço de viva manifestação democrática. Retomando o conceito de espaço público como local para a coexistência de diversas vozes sociais, podemos dizer que a poesia é seu correlato literário: um espaço linguístico marcado pelo signo da liberdade, em que as ausências apresentam-se como indicativos da pluralidade e da incerteza.

\section{POLÍTICA POÉTICA}

Doreen Massey, em seu livro Pelo espaço (2008), busca explicar por que o espaço não pode ser visto como uma instância estática e atemporal, mas sim como fruto da inter-relação entre os homens e o meio. A autora afirma que, enquanto a academia permanece fechada em uma conceitualização antiquada do que é o espaço, o senso comum sempre o percebeu como processo dinâmico e social. Para exemplificar essa teoria, ela se recorda de quando era criança e brincava de girar um globo, ansiosa para ver qual país seu dedo tocaria. Depois, imaginava como estaria a vida dos moradores daquele local: que horas eram, qual estação, o que faziam, quais seus hábitos...

Trago essa introdução porque acredito que é exatamente a essa brincadeira que nos remete as poesias de Craveirinha. Marcada pela subjetividade, a escrita do autor é também contextualizada com as questões particulares do espaço que habita. Lê-lo é uma experiência de queda, verso a verso, na situação política e social de Moçambique à época. Além disso, assim como a brincadeira da criança, a poesia do autor explicita a relação dos homens com o espaço, já que suas reflexões políticas sempre apontam para a necessidade de uma movimentação social em prol da construção de uma nação mais igualitária e livre. 
Marcada pela guerra, a poesia de Craveirinha traduz a angústia e a histeria de uma sociedade amedrontada. O poeta moçambicano vivenciou a guerra em seu interior. Sua poesia declama os horrores dos dez anos de luta por independência, as condições racistas que dominavam a política do país africano e a inconsistência da guerra por independência que resultou em guerras civis. Como afirma Carpinejar (2003), a escrita de Craveirinha não era engajada, mas, antes ainda, de sobrevivência. Viver em Moçambique exigia a tomada de posições, o medo constante e confirmado pelas reviravoltas políticas que continuavam mantendo o país longe da paz.

Contudo, embora a percepção dos escritores sobre a guerra varie muito, eles se encontram na busca por objetivos comuns e no uso da poesia como denúncia. A luta incondicional pela autonomia subjetiva e nacional e o reconhecimento da fragilidade humana norteiam a obra de Craveirinha, tornando-a, ao mesmo tempo, particular e universal - escrita de um espaço marginal, mas refletindo a condição humana em todo o mundo. Mais ainda, a poesia do autor apresenta a nostalgia como proposta política, uma ideia de que avançar exige reconhecer e respeitar o passado - expressa nas imagens telúricas e místicas, que remetem às tribos africanas.

Outra bandeira levantada pelo poeta era a da luta pela expressão livre. Escritor da ditadura, Craveirinha usava da metáfora para ludibriar e condenar as práticas de censura mantidas pelo governo de Salazar nas colônias portuguesas. Dessa forma, o poeta constrói um jogo metalinguístico em que palavras evocam o direito da fala e da liberdade, atacando o governo justamente com as armas proibidas. Por sua atuação política na Frente de Libertação de Moçambique (Frelimo), Craveirinha foi prisioneiro político entre 1964 e 1968, o que evidencia que sua escrita era, de fato, uma forma de combate.

Outra característica peculiar da escrita do autor é evidenciada por sua relação com o movimento modernista. Embora sejam claras as semelhanças entre sua obra e os textos vanguardistas europeus, é preciso assinalar que a distância geográfica e histórica ressignifica o movimento em África, organizando-o a partir de novos projetos e formas. Assim, o modernismo africano, tardio, é desenvolvido com base nas tendências europeias, mas encontra-se deslocado, estética e historicamente delas, tornando-se não mais um de seus braços, mas um outro sistema inteiramente.

A principal característica que afasta o modernismo africano do europeu é a presença das lutas nacionais nas obras artísticas do período. Os artistas do continente lutavam pelo reconhecimento nacional ao mesmo tempo em que as fronteiras eram dissolvidas pelo processo da globalização. Além disso, o projeto modernista africano propunha, na contramão do futurismo, um retorno às origens, a crenças e costumes tribais. Sendo assim, cabia a esses artistas encontrar um ponto comum entre o futuro que se apresentava com a promessa da liberdade e o passado ao qual queriam retornar. 
Podemos dizer, portanto, que o deslocamento é a principal marca da escrita modernista de Craveirinha. Artista do silenciamento da censura, testemunha da guerra e habitante da margem, o escritor soube usar como arma "a outra voz". A voz de quem não está no lugar que gostaria, mas que acredita na transformação; a voz de quem vê o mundo a partir da periferia, e, por isso mesmo, enxerga suas distorções e paradoxos com mais clareza.

\section{UMA NAÇÃO SE FAZ EM VERSOS}

Mesmo que o modernismo em África se caracterize pelo desejo de estabelecer patamares para a arte - e, em certo nível, para a política nas nações imaginadas, a utopia romântica que se viu na formação das literaturas nacionais americanas é substituída ali pela crítica consciente. Dessa forma, o projeto modernista moçambicano previa o debate e a democracia como metas artísticas e sociais, estabelecendo-se, pois, como espaço discursivo-social.

Por esse motivo, Craveirinha faz, em sua obra, uma crítica política ampla, retratando não apenas a realidade da colônia, mas também as propostas da Frelimo, à qual era filiado. Entretanto, minimizar o trabalho de construção literária do autor a uma bandeira política é desprezar as várias questões que perpassavam seus escritos. Afinal, as poesias de Craveirinha destacam a participação do indivíduo - apresentando, muitas vezes, questões autobiográficas - na luta pela autonomia.

Segundo Ângela Rego, "José Craveirinha é o cidadão antes de haver nação; é o homem liberto por vontade própria, antes da própria liberdade; é o poeta que se inventa entre grades e insetos, homem e formigas na construção do país." (REGO, 2008. p. 31) Dessa forma, o tema da independência nacional é atravessado pela libertação do próprio autor, que afirma, no poema Autobiografia (transcrito ao fim do trabalho), ter nascido muitas vezes, por redescobrir a si mesmo no contato com o novo. A relação de Craveirinha com o mundo é organizada, pois, a partir da integração do indivíduo na comunidade, suas afinidades com a terra e com o outro.

Ainda nesse poema, Craveirinha fala de sua relação com Moçambique: a terra natal, sua segunda mãe - responsável, assim como a primeira, por sua aparência africana, por seus conhecimentos telúricos, pelo reconhecimento de si nos outros homens de Mafalala. Dessa forma, o poeta não fala da terra como espaço geográfico, fronteira estipulada. Ao contrário, a terra é parte de si, "em termos de Pátria e de opção", humanizada por sua interação com os homens, pela existência ativa na luta de tantos deles.

Além disso, ao fim do texto, Craveirinha define a poesia como "meu refúgio, o meu País também", unindo a escrita à terra e demonstrando sua percepção de que um país é construído a cada dia. Mais que isso, ele concede à nação o caráter lúdico, rítmico, suave da poesia, aproximando a revolução da sensibilidade, o arco da lira, e demonstrando que as lutas 
nacionais não podem tentar transformar a Pátria em fronteira. $\mathrm{O}$ autor vai ainda mais além ao afirmar que o cidadão - da terra ou da poesia - deve esforçar-se "muitas vezes, altas horas a noite" para conquistar o pertencimento àquela nação.

É possível ver ainda que a construção do poema acompanha a vida do autor: do acaso - "nasci" - para a escolha - "em termos de opção" -, chegando, finalmente, à luta - "necessidade angustiosa e urgente". Esse mesmo caminho está proposto para a formação de Moçambique. Craveirinha, com sua sensibilidade poética, propõe que a nação que surge inclua as origens de seu povo e seu espaço, mas que também seja fruto da escolha, do debate e da luta democrática de seus cidadãos. Dessa forma, a tríade homem - poesia - nação organiza o texto, aproxima o sujeito do espaço e delimita um percurso ideológico para a construção da República de Moçambique.

\section{CÁRCERE E LIBERDADE: CONSTRUÇÕES IMAGINÁRIAS}

Craveirinha é autor de uma vasta obra, que inclui seis livros publicados entre 1964 e 1988. Considerando a impossibilidade de um único trabalho percorrer toda essa produção, escolhi trabalhar com dois poemas que se enquadram no objeto de estudo aqui apresentado, acreditando que eles ilustram com maestria a aplicação na teoria da literatura do conceito de espaço definido por geógrafos como Santos e Massey. Pretendo, portanto, estabelecer conexões mais específicas, discutindo como a obra do poeta integra os espaços social, discursivo, literário e histórico.

Os poemas escolhidos são "Quero ser tambor" e "Msaho de aniversário" (todos os poemas estão transcritos ao fim do trabalho). A escolha baseou-se no diálogo entre os textos, visto que todos se estruturam a partir de paradoxos e construções dialéticas, buscando integrar subjetividade e espaço público.

"Quero ser tambor", poema do livro Karingana ua Karingana (1974), traz no centro de sua construção o desejo do eu lírico de "ser tambor", invocando, desde o título, a relação do sujeito - marcada pelo verbo em primeira pessoa - com a ancestralidade e os costumes negros pré-colonização. No poema, a relação entre cárcere e liberdade, limitada, em uma primeira leitura, à metamorfose do sujeito, funciona também como metonímia para a luta nacional. Dessa forma, a imagem do tambor faz referência à Moçambique pré-colonização, agindo como metáfora para a Independência do país. "Ser tambor", nessa primeira leitura, é ser livre, é ter o direito de praticar costumes negros, é assumir a identidade cultural da nação, a partir de sua história e das crenças de seus habitantes.

Entretanto, o poema não se constrói apenas como a expressão livre do desejo, mas, principalmente, como o conflito do eu lírico. Isso fica evidente desde o título, em que o uso do verbo "querer" já explicita que, embora desejada, a ação não pode ser concretizada. Além disso, a organização do poema não caminha para a metamorfose almejada, mas se cons- 
trói a partir da dicotomia "afirmação" (centralizada na imagem do tambor) e "negação" (fortalecida pela partícula "nem"). O auge dessa disputa se dá a partir do décimo verso, em que a dupla negação "nem nada" abre espaço para versos que começam com "só tambor". Dessa forma, o poema se constrói como a contraposição daquilo que o eu lírico queria ser - mas não consegue - e aquilo que ele rejeita, mas é.

Assim, o conflito que se instaura é entre o ímpeto de voltar a ser um homem livre (como seus ancestrais) e a percepção de que tal retorno é impossível. Portanto, "Quero ser tambor" fala sobre um cárcere interior, imposto pelo espaço que habita, e a tentativa desesperada de um homem de transformá-lo, ao perceber que apagá-lo significaria apagar a história e, portanto, a si mesmo.

Nesse momento, a dicotomia cárcere/liberdade se desdobra no paradoxo natural/artificial. Pensando sobre isso, Flávia Bandeca Biazetto chama atenção para os verbos escolhidos por Craveirinha na construção do poema:

Ao se deter nos verbos da segunda estrofe: nascer, correr, temperar e forjar, nota-se que ações tão naturais da vida vão convergir para o verbo forjar, o que permite interpretar que o sistema colonial inventava uma realidade que não era a moçambicana e é daí que surge a reivindicação de ser tambor, isto é, africano. (BIAZETTO, 2007, p. 8)

Dessa forma, a ideia do cárcere se aproxima da artificialidade, enquanto a natureza evoca a liberdade. Sendo assim, o espaço moçambicano perde suas características naturais durante a colonização, pois é artificialmente moldado por Portugal. Por isso, o eu lírico rejeita a flor, o rio ou até mesmo a zagaia, já que, como observado por Biazzeto, esses símbolos foram corrompidos pela colonização, que transformou Moçambique em um simulacro de si mesmo.

O natural é representado, então, pelo homem africano e aquilo que ele produz. $\mathrm{O}$ eu lírico reflete acerca da capacidade do homem de se preservar mesmo durante a transformação. $\mathrm{O}$ tambor, imagem mais forte do poema, remete à natureza em sua "pele curtida" e em sua origem "cavada nos troncos duros". Mas sua importância vai além da lembrança do natural, pois ele é o símbolo da resistência, do grito, que, mesmo cansado e velho, rompe o silêncio imposto. $\mathrm{O}$ tambor é, assim, a ponte que une homem e natureza, sujeito e espaço, ecoando como a resistência das tradições que não se dissolvem, a força da vida africana que insiste em brotar na terra ocupada.

Em "Quero ser tambor", portanto, o cárcere aparece em todos os espaços, inclusive naqueles normalmente associados com a liberdade, como o rio, a mata ou a zagaia. Só fica imune a isso o indivíduo, que consegue romper a estrutura, justamente por ser agente dela. Dessa forma, ao perceber que no lugar do retorno deve estar presente a transformação, o homem produz o grito que saúda a liberdade. 
Já em "Msaho de aniversário", segundo poema escolhido para esse trabalho, os conflitos abordados em "Quero ser tambor" não desaparecem, mas cedem lugar para um sujeito mais ativo e envolvido socialmente. Ironicamente, nesse texto marcado pela subjetividade, o eu lírico não se coloca em cena até a última estrofe. Dessa forma, a descrição da miséria e da exploração, com que inicia o texto, é feita em terceira pessoa, como se o sujeito, de longe, observasse a tudo. Assim, "Msaho de aniversário" apresenta a visão que o eu lírico tem de uma sociedade reificada, incapaz de enxergar o outro e seu sofrimento, e absorta na manutenção de um sistema violento e cruel. Isso se faz presente no verso escrito em voz passiva - "minérios sempre descobertos" -, na borboleta que escreve sozinha a fábula dos homens subnutridos ou no silêncio do "tu", a quem faz alusão.

Entretanto, ao se colocar em cena, o poeta reestrutura a relação do sujeito com o mundo, esboçando a esperança em uma mudança possível. Tal ruptura com o mundo exploratório e reificado surge com o verso "mas eu". Simples, a combinação de uma conjunção adversativa e um pronome em primeira pessoa já explicita que o poeta é capaz de romper com o sistema, agindo opostamente ao "tu" que havia sido colocado na estrofe anterior. Em seguida, o poeta se aproxima do outro sujeito previamente apresentado no poema ao dizer que ele também é um negro chope subnutrido, mas que se mantém "invendido", resistente na luta contra a exploração e a covardia.

Craveirinha, portanto, exibe a escrita como sua arma na luta contra o sistema: ela vem como a fúria, o som inteiro, a impoética poesia. Para isso, além de dedicar o texto àqueles que permanecem em silêncio frente à injustiça, o autor nomeia o poema Msaho, aludindo aos versos cantados pelos timbileiros chopes e também ao movimento literário de Moçambique. Dessa forma, a escrita de Craveirinha não convida para a luta, mas se faz luta. A literatura é por si o combate, assim como a percepção das belezas do país (a borboleta que assiste a tudo) ou a persistência, que se transforma em resistência (a fábula de Moçambique, apresentada na segunda estrofe, é apenas a sobrevivência de seu povo).

Por isso, o poema metalínguistico se transforma em um manifesto que expõe como, por que e sobre o que escrever. Seus personagens são o povo de Moçambique (o negro chope, os moradores das "casas estranhas") e, ao apresentá-los, o poema os legitima e os localiza em um espaço social. Além disso, a descrição do espaço nas duas primeiras estrofes conduz para a descrição da poesia na última, propondo que a ela deve ser, assim como seu lugar de origem, feita da miséria, da coragem, da fúria.

Dessa forma, a poesia de Craveirinha se faz, ao mesmo tempo, como imagem e distorção da realidade. É seu reflexo por apresentar os desrespeitos e silêncios que ali existem, mas, ao mesmo tempo, por torná-los ícones e sons, os transforma, repelindo-se e confirmando que a mudança é possível. 


\section{CONSIDERAÇÕES FINAIS}

Este trabalho buscou apresentar como o conceito de espaço é definido por alguns autores, relacionando-o ao tempo pela lógica do cronótopo, de Bakhtin, e, finalmente, percebendo-o no interior do sistema poético. A poesia, por se configurar como uma ruptura na lógica espaço-temporal, apresenta consideráveis particularidades, organizando-se como um sistema no qual o tempo histórico é desconstruído e reapresentado.

O trabalho do poeta moçambicano José Craveirinha é exemplar na apresentação do espaço poético, pois combina a percepção subjetiva à luta coletiva por justiça e liberdade. Dessa forma, suas poesias se configuram como sistemas espaciais próprios, que refletem a condição histórica, mas, ao mesmo, subvertem-na, tornando-se instrumentos de resistência e reflexão.

\section{REFERÊNCIAS BIBLIOGRÁFICAS}

BAKHTIN, Mikhail. Questões de literatura e estética. São Paulo: Unesp. 1993.

BIAZETTO, Flávia Bandeca. O som ressonante dos tambores. In: Revista Crioula, n. 2, São Paulo: Faculdade de Filosofia, Letras e Ciências Humanas da Universidade de São Paulo, 2007

BOSI, Alfredo. O ser e o tempo da poesia. São Paulo: Companhia das Letras. 2000.

CANDIDO, Antonio. O direito à literatura. In: CANDIDO, Antonio. Vários escritos. Rio de Janeiro: Ouro sobre Azul, 1977.

CRAVEIRINHA, José. Karingana ua Karingana. Lourenço Marques: Academica. 1974.

MASSEY, Doreen. Pelo espaço: uma nova política da espacialidade. Rio de Janeiro: Bertrand Brasil. 2008.

MOISES, Massaud. A criação literária: poesia. São Paulo: Cultrix. 1998.

PAZ, Octavio. A outra voz. São Paulo: Siciliano. 2001.

REGO, Ângela Cristina de Souza. Da poesia de intervenção ao signo erótico amoroso: alteridade e subjetividade na poesia de Carlos Drummond de Andrade e José Craveirinha. Tese (Doutorado em Literatura Comparada). Universidade Federal Fluminense, Niterói, 2008.

SANTOS, Milton. Metamorfoses do espaço habitado. São Paulo: Hucitec. 1988. 


\section{APÊNDICE: POEMAS ANALISADOS NO TRABALHO AUTOBIOGRAFIA - JOSÉ CRAVEIRINHA}

Nasci a primeira vez em 28 de Maio de 1922. Isto num domingo. Chamaram-me Sontinho, diminutivo de Sonto. Isto por parte da minha mãe, claro. Por parte do meu pai, fiquei José. Aonde? Na Av. Do Zihlahla, entre o Alto Maé e como quem vai para o Xipamanine. Bairros de quem? Bairros de pobres.

Nasci a segunda vez quando me fizeram descobrir que era mulato...

A seguir, fui nascendo à medida das circunstâncias impostas pelos outros. Quando o meu pai foi de vez, tive outro pai: seu irmão.

E a partir de cada nascimento, eu tinha a felicidade de ver um problema a menos e um dilema a mais. Por isso, muito cedo, a terra natal em termos de Pátria e de opção. Quando a minha mãe foi de vez, outra mãe: Moçambique. A opção por causa do meu pai branco e da minha mãe preta.

Nasci ainda outra vez no jornal O Brado Africano. No mesmo em que também nasceram Rui de Noronha e Noémia de Sousa.

Muito desporto marcou-me o corpo e o espírito. Esforço, competição, vitória e derrota, sacrifício até à exaustão. Temperado por tudo isso.

Talvez por causa do meu pai, mais agnóstico do que ateu. Talvez por causa do meu pai, encontrando no Amor a sublimação de tudo. Mesmo da Pátria. Ou antes: principalmente da Pátria. Por parte de minha mãe, só resignação. Uma luta incessante comigo próprio. Autodidacta.

Minha grande aventura: ser pai. Depois, eu casado. Mas casado quando quis. E como quis. Escrever poemas, o meu refúgio, o meu País também. Uma necessidade angustiosa e urgente de ser cidadão desse País, muitas vezes, altas horas a noite.

(Disponível em: http://pt.wikipedia.org/wiki/Jos\%C3\%A9_Craveirinha)

\section{Quero ser tambor - José Craveirinha}

Tambor está velho de gritar

Oh velho Deus dos homens

deixa-me ser tambor

corpo e alma só tambor

só tambor gritando na noite quente dos trópicos.

Nem flor nascida no mato do desespero

Nem rio correndo para o mar do desespero

Nem zagaia temperada no lume vivo do desespero

Nem mesmo poesia forjada na dor rubra do desespero.

Nem nada!

Só tambor velho de gritar na lua cheia da minha terra

Só tambor de pele curtida ao sol da minha terra

Só tambor cavado nos troncos duros da minha terra.

$\mathrm{Eu}$

Só tambor rebentando o silêncio amargo da Mafalala 
Só tambor velho de sentar no batuque da minha terra Só tambor perdido na escuridão da noite perdida.

Oh velho Deus dos homens

eu quero ser tambor

e nem rio

e nem flor

e nem zagaia por enquanto

e nem mesmo poesia.

Só tambor ecoando como a canção da força e da vida

Só tambor noite e dia

dia e noite só tambor

até à consumação da grande festa do batuque!

Oh velho Deus dos homens

deixa-me ser tambor

só tambor!

\section{Msaho de aniversário - José Craveirinha}

Negro chope

subnutrido canta a noite de lua cheia

e na timbila de ânforas de massala

toca audível msaho da virgem tonga.

E borboleta amarela

no estrénuo palpitar das asas

sozinha escreve na atmosfera agrimensurada

a fábula incrível das novas casas estranhas

e dos minérios sempre descobertos pelos outros

nas minhas terras familiares de xingombela

ao norte e ao sul do rio

agora chamadas claim.

E tu continuarás

mesmo assim

no teu dúbio silêncio.

Mas eu

do primeiro ao último invendido cromossoma

desnutrido moçambicano da cabeça aos pés

da concessão dos alvarás de exploração dos jazigos de Moçambique

e da tua conforme covardia

farei para ti em mil novecentos e sessenta e um

inteiro o som e completa a fúria

desta minha inexorável

impoética poesia 